\title{
Modelling of Multi-Objective Transshipment Problem with Fuzzy Goal Programming
}

\author{
Selçuk Alp ${ }^{1 *}$ and Tuğba Kiral Özkan ${ }^{2}$ \\ ${ }^{1}$ Yıldız Technical University, Department of Industrial Engineering \\ ${ }^{2}$ Bahçeşehir University, Faculty of Educational Sciences \\ 1*alp@yildiz.edu.tr, ${ }^{2}$ tugba.kiral@es.bahcesehir.edu.tr
}

\begin{abstract}
The purpose of the transportation problem is trying to find the best route to meet the demands by using the supply points with capacity. While the Transportation problem only allowed products to be conveyed directly from the supply centers to demand centers, problem of transshipment transfer centers are also used.

Linear programming methods can be used to solve the transportation problems. However, in the presence of numerical targets to achieve; Goal programming method is used instead of Linear Programming. Goal programming is a method applied to linear programming problems with a large number of goals and objectives. On the contrary to linear programming methods which is optimizing an objective; goal programming, used to deliver results for conflicting objectives by minimizing the deviation between objective values and the realized results. Fuzzy Goal Programming approach is used to solve problems if the exact value is not measured for the objectives and constraints.

The purpose of this article is to put forth that the fuzzy goal programming which we can accept as one of the best decision-making models that can be used under the fuzzy and reveal the solution, can be used for the modeling of a transshipment problem.
\end{abstract}

Keywords: Fuzzy Goal programming, Transshipment Problem

\section{Introduction}

The businesses create a chain including suppliers, distributors and customers to convey their products to their customers. In order to reduce the expenses and increase profitability in this supplier chain, they try to minimize the transportation expenses that have an important place in its total expenses. By conveying the products suitable for the needs of customers in the required amount on time by minimum cost, intrabusiness conveyance problem optimization for the businesses that want to obtain rivalry advantage gains importance [1].

The operational research models are the mathematical methods used in the solution of this and similar optimization problems. Goal Programming (GP) that is one of these models is a multi-objective Linear Programming (LP) model aiming to minimize simultaneously the deviations from the targets. The emergence of GP is based on the studies made by Charnes, Cooper and Ferguson in 1995. There were a few number of GP application up to the midst of 1970s in the literature. During this period, there were some developments based on the studies of Lee and Ignizio. In the studies performed by Romeo, Schniederjans and Tamiz, it has been revealed that there are many implementation area of GP [2].

In many cases related to the real world, the decision makers are face with the targets and goals that are not completely definite. In such cases, the fuzzy set theory for decision making is suitable for solution. Fuzzy Goal Programming (FGP) that is formed by the

Received (June 22, 2017), Review Result (November 20, 2017), Accepted (December 28, 2017)

* Corresponding Author 
implementation of fuzzy sets theory in GP is a method used in the cases that indefinite targets are in question [3].

In the following years, some researchers such as Hannan [4], Tiwari et al., [5], Yang et al., [6], Chen and Larbani [7] carried out some studies about the problem formulation in the field of FGP and the fuzzy superiorities of fuzzy targets and they developed the solution suggestions belonging to them. The problem discussed in the study and known as transshipment problem deals with the shipment problem with the least cost from more than one source to the target by using transfer points.

FGP has been used in many different areas (topics). Some of which can be listed as follows: Supply chain (Kumar et al., [13], Selim et al., [14]), portfolio selection (Parra et al., [15], Sharma et al., [16]), traffic management (Rout [17]), solid waste management (Biswas and De [18], Kinoshita et al., [19]), human resource allocation (Mehrolhassani and Jahromi [20]), agricultural production planning (Augustynczik et al., [21], Mishra and Singh [22].

There are many solution methods of transshipment problem. In this study, the capacities of the transshipment points and by accepting the shipment between the units as financial constraint, it has been aimed to find optimal solution with fuzzy goal programming model.

\section{Mathematical Model}

The main idea of GP is to find solutions to obtain a predefined target value for one or more goal function. If there is no solution achieving the predefined targets in all goal functions, it is to find solutions having minimum targeted deviation. On the other hand, if there is a solution achieving the desired targets, the goal of GP is to define this definite solution. This is partly similar to the approach in the satisfactory decision making approach and the obtained solution is a satisfactory solution that can be different from an optimal solution [8].

In the model of GP, its goals and functions and the access values of them and the constraints of then are expressed as deterministic [9]. Access values, the preference priority ordering and the relative weights are generally determined with the subjective judgments of the decision maker. When Fuzzy sets theory is applied to GP model, the access levels of the targets and the preference priorities can be described with the indefinite expressions. Fuzzy sets theory allows describing the access levels that can be expressed according to the natural structure of a language such as "approximately", "equal to..." and "too smaller than..." for the targets of the decision makers based on their subjective judgements. Such kinds of descriptions related to the targets are discussed with the membership functions in fuzzy sets. So, the feature of GP model that is based on satisfactory thought more than an optimization thought is come to the forefront.

FGP model is discussed in two ways according to the priority structure of the targets. The first one of them is the FGP model in which all the targets are equal priority. In this model, a solution that satisfies all targets simultaneously. The second one is the preference preemptive FGP model in which the targets are ordered in preference priorities. In this model, it is tried to define a solution taking into account the preference priority of the decision maker. The main difference between conventional cluster theory and fuzzy sets theory is their functions. While a conventional cluster can only be described with a membership function, a fuzzy cluster can be described with infinitely membership function. Membership functions related to fuzzy sets can be classified as intermittent and continuous, parametric and nonparametric, symmetrical and non-symmetrical. Fuzzy targets have been described with membership functions with different features in the literature as triangular, isosceles, piecewise linear, concave shaped piecewise linear, semi-concave shaped piecewise linear, s-shaped piecewise linear and cambered shaped piecewise linear.

Due to the differences in the structure of goal functions and the membership functions used, there is various solution approaches developed for FGP models. These approaches 
can be listed as Narasimhan Approach, Hannan Approach, Yang, Ignizio and Kim Approach, Tiwari, Dharmar and Rao Approach, Chen Approach, Tiwari, Dharmar and Rao's Social Model Approach. Fuzzy decision approach defined by Bellmann and Zadeh [10] forms the basis of this approach.

In this study, Hannan Approach and Chen Approach will be discussed with Triangular Membership Functions and the application will be solved by using these methods.

\subsection{Hannan Approach}

This method developed by Hannan is used in the cases where the fuzzy targets are described with triangular membership functions. Hannan succeeded in formulating FGP model as a unique LP model with a theorem in the shape. Here, the solution value of the sub-problems shows the highest membership degree element of the fuzzy decision cluster. In order to solve FGP model, the sub-problems can be described as follows:

$$
\begin{aligned}
& \left.\begin{array}{l}
1-\frac{b_{i}-(A x)_{i}}{d_{i}} \geq \lambda \\
b_{i}-d_{i} \leq(A x)_{i} \leq b_{i}
\end{array}\right\} \\
& \left.\begin{array}{l}
1-\frac{(A x)_{i}-b_{i}}{d_{i}} \geq \lambda \\
b_{i} \leq(A x)_{i} \leq b_{i}+d_{i}
\end{array}\right\} \\
& \begin{array}{l}
\lambda \in[0,1] \\
x \geq 0
\end{array}
\end{aligned}
$$

FGP model can be stated as a unique LP problem as follows (Hannan, 1981)

Maximize $\lambda$

Subject to

$$
\begin{aligned}
& \frac{(A x)_{i}}{d_{i}}+d_{i}^{-}-d_{i}^{+}=\frac{b_{i}}{d_{i}} \\
& \lambda+d_{i}^{-}+d_{i}^{+} \leq 1 \\
& d_{i}^{-} \times d_{i}^{+}=0 \\
& x_{j}, \lambda, d_{i}^{-}, d_{i}^{+} \geq 0 \quad i=1,2, \ldots, m, j=1,2, \ldots, n
\end{aligned}
$$

Here, $\lambda$ variable shows the access level to the fuzzy targets. For the complete satisfaction of a fuzzy target $\lambda=1$ or $d_{i}^{-}=d_{i}^{+}=0$ condition must be ensured.

\subsection{Chen Approach}

The approach suggested by Chen is a preference priority approach in which the fuzzy targets are described with the triangular membership functions and it aims to reduce the transition load. Chen succeeded in reducing FGP problem in preference priority to a unique LP problem.

The degree of a fuzzy target reaching to the access level is at least 0 and at most 1 . Besides, the access levels of the fuzzy targets are in $\alpha$-section cluster in the value of $\alpha=1$. In Chen approach, the maximum deviations including membership degrees of the fuzzy targets that can be equal to 1 at most are minimized [12]. Because maximizing the 
membership degree of a fuzzy target is equal to the thought of minimizing the degree of not being member if a fuzzy target. From this perspective, the best solution of preference preemptive FGP problems can be defined by solving the following problem.

$$
\min \lambda^{\prime}=\left[\max _{i}\left\{\left|1-\mu_{i}(A x)\right|\right\}\right]
$$

Subject to

$$
\begin{aligned}
& b_{i}-d_{i} \leq(A x)_{i} \leq b_{i}+d_{i} \\
& x_{i} \geq 0
\end{aligned}
$$

Here, the variable showing not being a member of fuzzy targets is described as the equality. The triangular membership functions describing the fuzzy target can be discussed as increasing piece (section) and decreasing (section) according to the membership degree and the absolute value mark given in the above model can be used. It is clear that the decreasing piece of the membership function is described with the function of $1-\left(\left(A(x)_{i}-b_{i}\right) /\left(d_{i}\right)\right)$ and the increasing piece is described with the function of $1-\left(\left(A(x)_{i}-b_{i}\right) /\left(d_{i}\right)\right)$. For this reason, the mentioned model is expressed with;

Maximize $\lambda$

Subject to

$$
\begin{aligned}
& \lambda^{\prime} \geq\left(1-\frac{b_{i}-(A x)_{i}}{d_{i}}\right)-1 \quad \Rightarrow \lambda^{\prime} \geq \frac{(A x)_{i}-b_{i}}{d_{i}} \\
& \lambda^{\prime} \geq 1-\left(1-\frac{(A x)_{i}-b_{i}}{d_{i}}\right)-1 \Rightarrow \lambda^{\prime} \geq \frac{b_{i}-(A x)_{i}}{d_{i}} \\
& b_{i}-d_{i} \leq(A x)_{i} \leq b_{i}+d_{i} \\
& \lambda^{\prime} \in[0,1] \\
& x_{i} \geq 0
\end{aligned}
$$

\section{Application}

In this study, a transshipment problem has been discussed with certain targets. In the application [11], 3 sources that are suppliers, potential 5 facilities and 5 Distributing Centers that are 2 transmission points and finally 4 targets that is to say customers. 


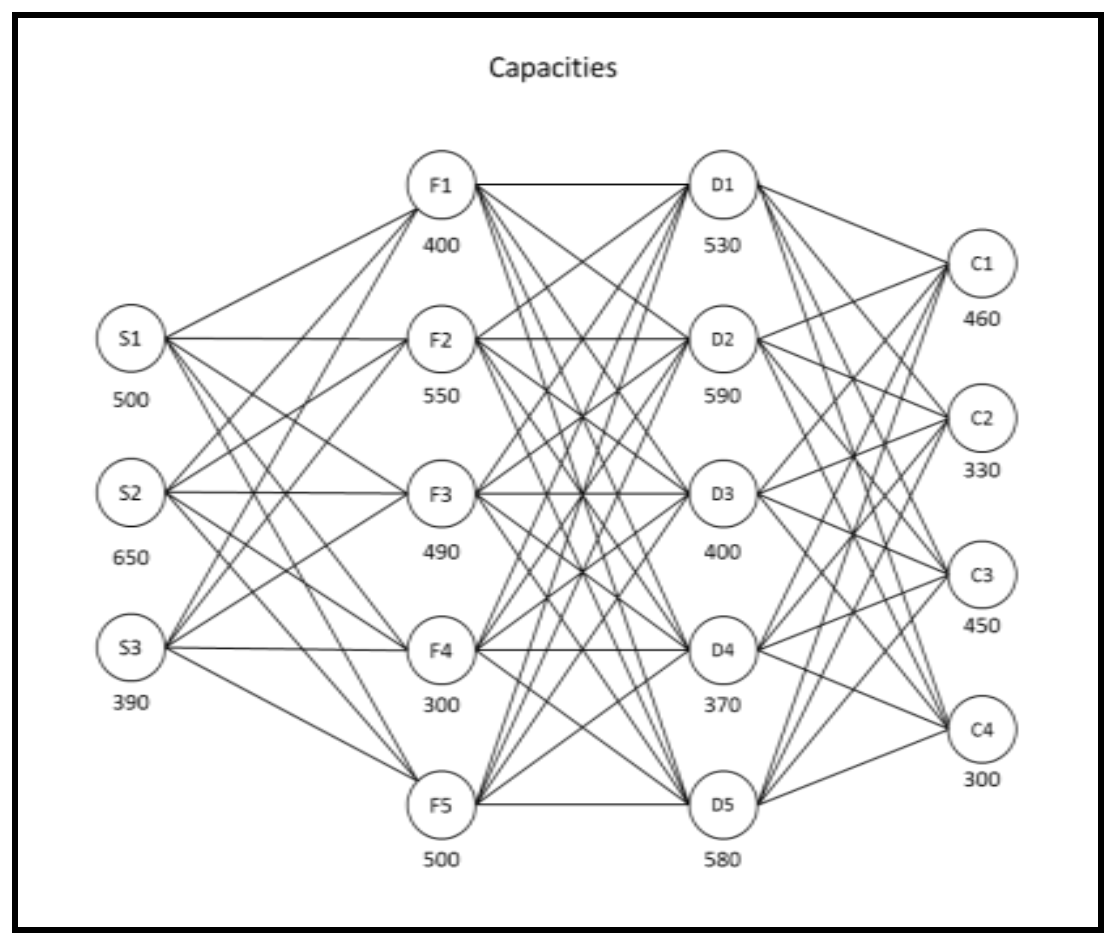

Figure 1. Capacities

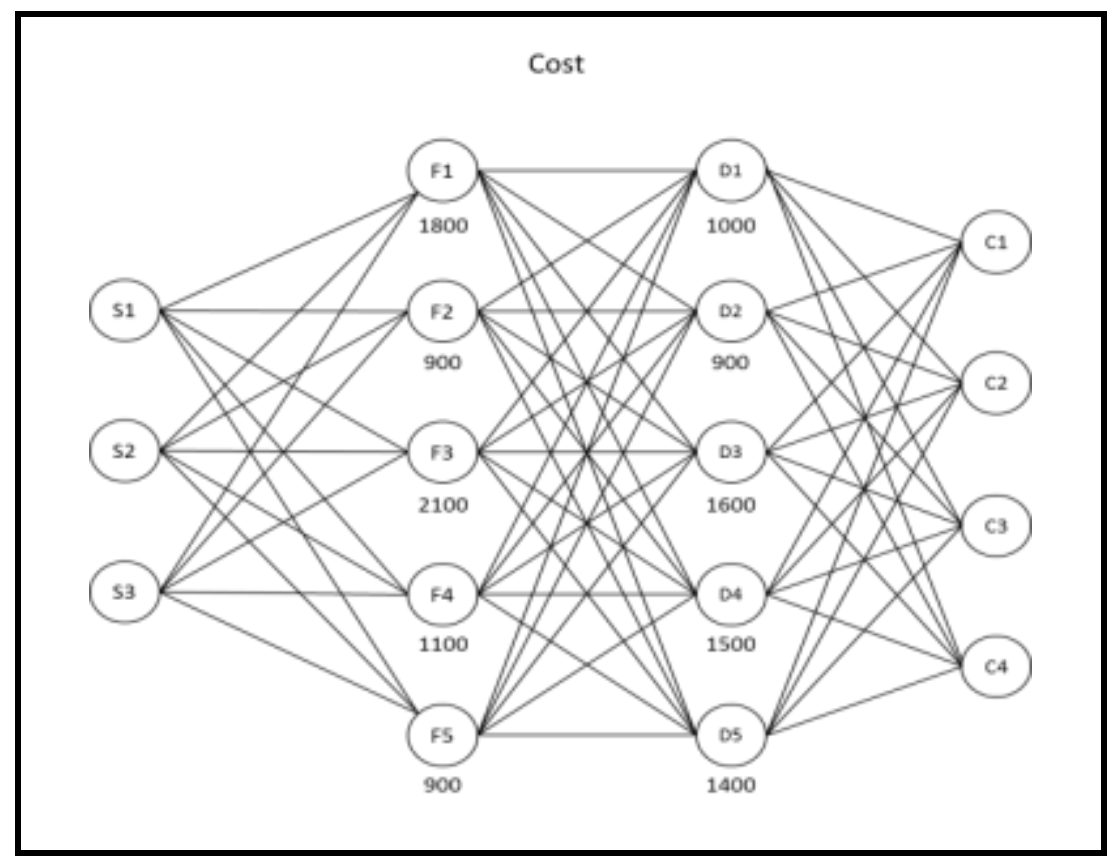

Figure 2. Fixed Cost of Facilities and DC's

Table 1. An Unit Cost of Transportation from Suppliers to Facilities

\begin{tabular}{cccccc}
\hline \multirow{2}{*}{ Supplier } & \multicolumn{5}{c}{ Facilities } \\
\cline { 2 - 6 } & F1 & F2 & F3 & F4 & F5 \\
\hline S1 & 5 & 6 & 4 & 7 & 5 \\
S2 & 6 & 5 & 6 & 6 & 8 \\
S3 & 7 & 6 & 3 & 9 & 6 \\
\hline
\end{tabular}


Table 2. An Unit Cost of Transportation from Facilities to Distributing Centers

\begin{tabular}{cccccc}
\hline \multirow{2}{*}{ Facilities } & \multicolumn{5}{c}{ Distributing Center } \\
\cline { 2 - 6 } & D1 & D2 & D3 & D4 & D5 \\
\hline F1 & 5 & 8 & 5 & 8 & 5 \\
F2 & 8 & 7 & 8 & 6 & 8 \\
F3 & 4 & 7 & 4 & 5 & 4 \\
F4 & 3 & 5 & 3 & 5 & 3 \\
F5 & 5 & 6 & 6 & 8 & 3 \\
\hline
\end{tabular}

Table 3. An Unit Cost of Transportation from Distributing Centers to Customers

\begin{tabular}{ccccc}
\hline \multirow{2}{*}{ Distributing Center } & \multicolumn{4}{c}{ Customers } \\
\cline { 2 - 5 } & C1 & C2 & C3 & C4 \\
\hline D1 & 7 & 4 & 5 & 6 \\
D2 & 5 & 4 & 6 & 7 \\
D3 & 7 & 5 & 3 & 6 \\
D4 & 3 & 5 & 6 & 4 \\
D5 & 4 & 6 & 5 & 7 \\
\hline
\end{tabular}

In the application, there are 4 factories and 4 distribution centers. The capacities of the sources, facilities and distributing centers are given in Figure 1 and the fixed costs of facilities and distributing centers are given in Figure 2. The unit cost of transportation between the suppliers and facilities is given in Table 1, the unit cost of transportation between the facilities and distributing centers is given in Table 2 and the unit cost of transportation between the distributing centers and the customers are given in Table 3 . The suggested model has been formed by using this data. The model formed has been solved by using WinQSB implementation program separately with Hannan ve Chen approaches and the results have been found.

\subsection{Mathematical Model}

Decision makers wanted to have 4000 TL for each of the facilities and distribution centers to be established. Also, the total cost of transport is $20000 \mathrm{TL}$. The tolerance values for each of the facilities and distribution centers to be established were $300 \mathrm{TL}$ and the transport costs to be $1100 \mathrm{TL}$. Decision makers want to set up to 4 facilities and 4 distribution centers.

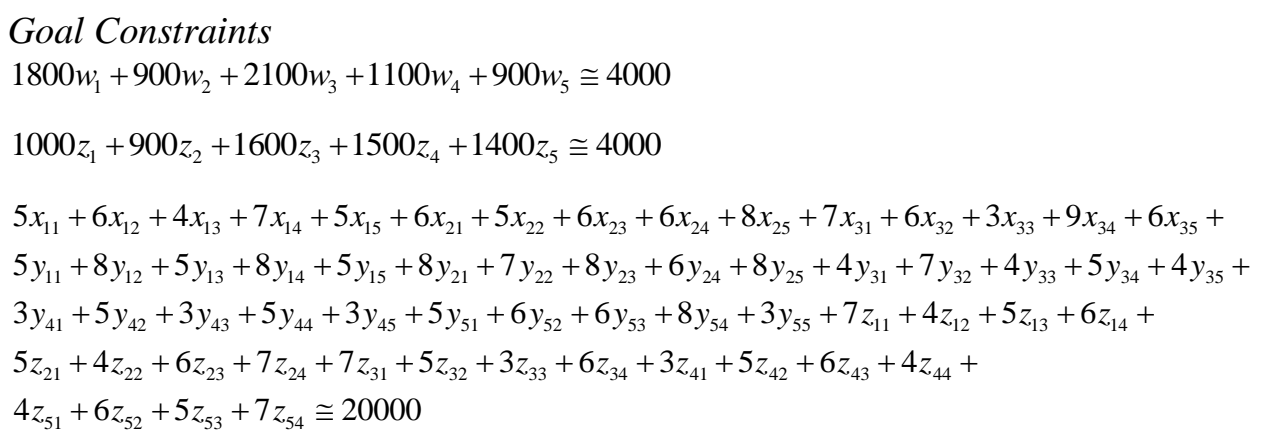

\section{Absolute Constraints}

a) Constraints of using all of the sources

$$
\sum_{j=1}^{5} x_{i j}=a_{i} \quad(i=1, \ldots, 3)
$$


$x_{11}+x_{12}+x_{13}+x_{14}+x_{15}=500$

$x_{21}+x_{22}+x_{23}+x_{24}+x_{25}=650$

$x_{31}+x_{32}+x_{33}+x_{34}+x_{35}=390$

Constraints of not exceeding the capacitances of shipped from facilities to DC's if each facility takes place

$$
\left.\begin{array}{c}
\sum_{k=1}^{5} y_{j k} \leq a_{j} w_{j}(j=1, \ldots, 5) \\
y_{11}+y_{12}+y_{13}+y_{14}+y_{15} \leq 400 w_{1} \\
y_{21}+y_{22}+y_{23}+y_{24}+y_{25} \leq 550 w_{2} \\
y_{31}+y_{32}+y_{33}+y_{34}+y_{35} \leq 490 w_{3} \\
y_{41}+y_{42}+y_{43}+y_{44}+y_{45} \leq 300 w_{4} \\
y_{51}+y_{52}+y_{53}+y_{54}+y_{55} \leq 500 w_{5}
\end{array}\right\} \begin{aligned}
& y_{11}+y_{12}+y_{13}+y_{14}+y_{15}-400 w_{1} \leq 0 \\
& y_{21}+y_{22}+y_{23}+y_{24}+y_{25}-550 w_{2} \leq 0 \\
& y_{31}+y_{32}+y_{33}+y_{34}+y_{35}-490 w_{3} \leq 0 \\
& y_{51}+y_{52}+y_{53}+y_{54}+y_{45}-300 w_{4} \leq 0
\end{aligned}
$$

b) Constraints of not exceeding the capacitances of shipped from DC's to customers if each DC takes

$$
\sum_{l=1}^{4} z_{k l} \leq c_{k} z_{k}(k=1, \ldots, 5)
$$

$$
\left.\begin{array}{l}
z_{11}+z_{12}+z_{13}+z_{14} \leq 530 z_{1} \\
z_{21}+z_{22}+z_{23}+z_{24} \leq 590 z_{2} \\
z_{31}+z_{32}+z_{33}+z_{34} \leq 400 z_{3} \\
z_{41}+z_{42}+z_{43}+z_{44} \leq 370 z_{4} \\
z_{51}+z_{52}+z_{53}+z_{54} \leq 580 z_{5}
\end{array}\right\} \quad \begin{aligned}
& z_{11}+z_{12}+z_{13}+z_{14}-530 z_{1} \leq 0 \\
& z_{21}+z_{22}+z_{23}+z_{24}-590 z_{2} \leq 0 \\
& z_{31}+z_{32}+z_{33}+z_{34}-400 z_{3} \leq 0 \\
& z_{41}+z_{42}+z_{43}+z_{44}-370 z_{4} \leq 0 \\
& z_{51}+z_{52}+z_{53}+z_{54}-580 z_{5} \leq 0
\end{aligned}
$$

c) Constraints of maximum number of facilities

$$
\sum_{j=1}^{5} w_{j} \leq 4
$$

$w_{1}+w_{2}+w_{3}+w_{4}+w_{5} \leq 4$

\section{d) Constraints of maximum number of DC}

$$
\sum_{j=1}^{5} z_{j} \leq 4
$$

$z_{1}+z_{2}+z_{3}+z_{4}+z_{5} \leq 4$

e) Constraints of providing all of the customer requests

$$
\sum_{k=1}^{5} z_{k l}=d_{l}(l=1, . ., 4)
$$

$$
\begin{aligned}
& z_{11}+z_{21}+z_{31}+z_{41}+z_{51}=460 \\
& z_{12}+z_{22}+z_{32}+z_{42}+z_{52}=330 \\
& z_{13}+z_{23}+z_{33}+z_{43}+z_{53}=450 \\
& z_{14}+z_{24}+z_{34}+z_{44}+z_{54}=300
\end{aligned}
$$

f) Constraints of not exceeding the capacitances of shipped from sources to facilities

$$
\sum_{i=1}^{3} x_{i j} \geq \sum_{k}^{5} y_{j k}(j=1, \ldots, 5)
$$




$$
\left.\begin{array}{l|l}
x_{11}+x_{21}+x_{31} \geq y_{11}+y_{12}+y_{13}+y_{14}+y_{15} \\
x_{12}+x_{22}+x_{32} \geq y_{21}+y_{22}+y_{23}+y_{24}+y_{25} \\
x_{13}+x_{23}+x_{33} \geq y_{31}+y_{32}+y_{33}+y_{34}+y_{35} \\
x_{14}+x_{24}+x_{34} \geq y_{41}+y_{42}+y_{43}+y_{44}+y_{45} \\
x_{15}+x_{25}+x_{35} \geq y_{51}+y_{52}+y_{53}+y_{54}+y_{55}
\end{array}\right\} \begin{aligned}
& x_{11}+x_{21}+x_{31}-y_{11}-y_{12}-y_{13}-y_{14}-y_{15} \geq 0 \\
& x_{12}+x_{22}+x_{32}-y_{21}-y_{22}-y_{23}-y_{24}-y_{25} \geq 0 \\
& x_{13}+x_{23}+x_{33}-y_{31}-y_{32}-y_{33}-y_{34}-y_{35} \geq 0 \\
& x_{14}+x_{24}+x_{34}-y_{41}-y_{42}-y_{43}-y_{44}-y_{45} \geq 0 \\
& x_{15}+x_{25}+x_{35}-y_{51}-y_{52}-y_{53}-y_{54}-y_{55} \geq 0
\end{aligned}
$$

g) Constraints of not exceeding the capacitances of shipped from facilities to DC's

$$
\begin{aligned}
& \sum_{j=1}^{5} y_{j k} \geq \sum_{l}^{4} z_{k l}(k=1, . ., 5) \\
& y_{11}+y_{21}+y_{31}+y_{41}+y_{51} \geq z_{11}+z_{12}+z_{13}+z_{14} \quad y_{11}+y_{21}+y_{31}+y_{41}+y_{51}-z_{11}-z_{12}-z_{13}-z_{14} \geq 0 \\
& y_{12}+y_{22}+y_{32}+y_{42}+y_{52} \geq z_{21}+z_{22}+z_{23}+z_{24} \quad y_{12}+y_{22}+y_{32}+y_{42}+y_{52}-z_{21}-z_{22}-z_{23}-z_{24} \geq 0 \\
& \left.y_{13}+y_{23}+y_{33}+y_{43}+y_{53} \geq z_{31}+z_{32}+z_{33}+z_{34}\right\} \quad y_{13}+y_{23}+y_{33}+y_{43}+y_{53}-z_{31}-z_{32}-z_{33}-z_{34} \geq 0 \\
& y_{14}+y_{24}+y_{34}+y_{44}+y_{54} \geq z_{41}+z_{42}+z_{43}+z_{44} \quad y_{14}+y_{24}+y_{34}+y_{44}+y_{54}-z_{41}-z_{42}-z_{43}-z_{44} \geq 0 \\
& y_{15}+y_{25}+y_{35}+y_{45}+y_{55} \geq z_{51}+z_{52}+z_{53}+z_{54} \quad y_{15}+y_{25}+y_{35}+y_{45}+y_{55}-z_{51}-z_{52}-z_{53}-z_{54} \geq 0 \\
& w_{j}=\{0,1\} \quad(j=1, \ldots, 5) \\
& z_{k}=\{0,1\} \quad(k=1, \ldots, 5) \\
& x_{i j}, y_{j k}, z_{k l} \geq 0 \quad(i=1, . ., 3)(j=1, \ldots, 5)(k=1, \ldots, 5)(l=1, \ldots, 4)
\end{aligned}
$$

$x_{i j}:$ quantity produced at facility $\mathrm{j}$ using material from supplier $\mathrm{i}$

$y_{j k}:$ amount shipped from facility $\mathrm{j}$ to DC $\mathrm{k}$

$z_{k l}:$ amount shipped from DC $\mathrm{k}$ to customer 1

$w_{j}=\left\{\begin{array}{ll}1, & \text { if productiontakes place at facility } j \\ 0, & \text { otherwise }\end{array} \quad z_{k}= \begin{cases}1, & \text { if DC } k \text { is opened } \\ 0, & \text { otherwise }\end{cases}\right.$

\subsection{Fuzzy Goal Programming Model using Hannan Approach}

According to Hannan approach, FGP model has been formed as follows.

Maximize

\section{Subject to}

$$
\begin{aligned}
& 1800 w_{1}+900 w_{2}+2100 w_{3}+1100 w_{4}+900 w_{5}+d_{1}^{-}-d_{1}^{+}=4000 \\
& 1000 z_{1}+900 z_{2}+1600 z_{3}+1500 z_{4}+1400 z_{5}+d_{2}^{-}-d_{2}^{+}=4000 \\
& 5 x_{11}+6 x_{12}+4 x_{13}+7 x_{14}+5 x_{15}+6 x_{21}+5 x_{22}+6 x_{23}+6 x_{24}+8 x_{25}+7 x_{31}+6 x_{32}+3 x_{33}+9 x_{34}+6 x_{35}+ \\
& 5 y_{11}+8 y_{12}+5 y_{13}+8 y_{14}+5 y_{15}+8 y_{21}+7 y_{22}+8 y_{23}+6 y_{24}+8 y_{25}+4 y_{31}+7 y_{32}+4 y_{33}+5 y_{34}+4 y_{35}+ \\
& 3 y_{41}+5 y_{42}+3 y_{43}+5 y_{44}+3 y_{45}+5 y_{51}+6 y_{52}+6 y_{53}+8 y_{54}+3 y_{55}+7 z_{11}+4 z_{12}+5 z_{13}+6 z_{14}+ \\
& 5 z_{21}+4 z_{22}+6 z_{23}+7 z_{24}+7 z_{31}+5 z_{32}+3 z_{33}+6 z_{34}+3 z_{41}+5 z_{42}+6 z_{43}+4 z_{44}+ \\
& 4 z_{51}+6 z_{52}+5 z_{53}+7 z_{54}+d_{3}^{-}-d_{3}^{+}=20000 \\
& \lambda+d_{1}^{-}+d_{1}^{+} \leq 1 \\
& \lambda+d_{2}^{-}+d_{2}^{+} \leq 1 \\
& \lambda+d_{3}^{-}+d_{3}^{+} \leq 1
\end{aligned}
$$

Absolute Constraints given in the equations from number 17 to 27 . 


\subsection{Fuzzy Goal Programming Model using Chen Approach}

According to Chen approach, FGP model has been formed as follows.

Maximize $\lambda$

Subject to

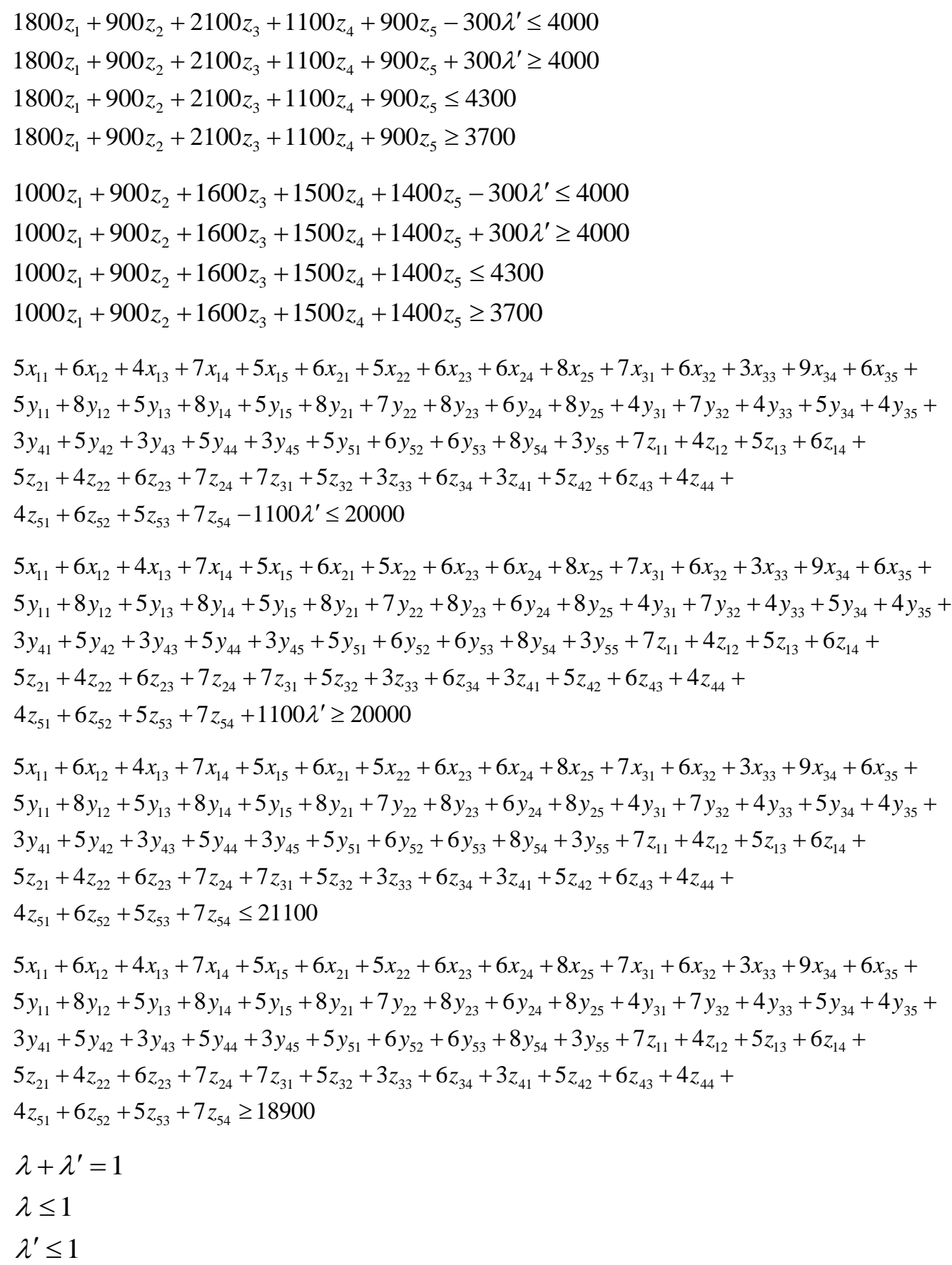

Absolute Constraints given in the equations from number 17 to 27 .

\subsection{Results}

Here as a result of the solution of both models, the results given in Table 4 were found. 
Table 4. The Results of Decision Variables

\begin{tabular}{ccccc}
\hline $\begin{array}{c}\text { From Supplier } \\
\text { to Facility }\end{array}$ & $\begin{array}{c}\text { From Facility } \\
\text { to DC }\end{array}$ & $\begin{array}{c}\text { From DC } \\
\text { to Customer }\end{array}$ & Facility & DC \\
\hline $\mathrm{X} 15=500$ & $\mathrm{Y} 22=550$ & $\mathrm{Z} 22=330$ & $\mathrm{~W} 1=0$ & $\mathrm{Z} 1=0$ \\
$\mathrm{X} 22=550$ & $\mathrm{Y} 32=10$ & $\mathrm{Z} 24=230$ & $\mathrm{~W} 2=1$ & $\mathrm{Z} 2=1$ \\
$\mathrm{X} 23=100$ & $\mathrm{Y} 33=400$ & $\mathrm{Z33}=400$ & $\mathrm{~W} 3=1$ & $\mathrm{Z} 3=1$ \\
$\mathrm{X} 33=390$ & $\mathrm{Y} 35=80$ & $\mathrm{Z} 51=460$ & $\mathrm{~W} 4=0$ & $\mathrm{Z} 4=0$ \\
& $\mathrm{Y} 55=500$ & $\mathrm{Z} 53=50$ & $\mathrm{~W} 5=1$ & $\mathrm{Z} 5=1$ \\
& & $\mathrm{Z} 54=70$ & & \\
\hline
\end{tabular}

Amount shipped were showed in Figure 3 according to the results.

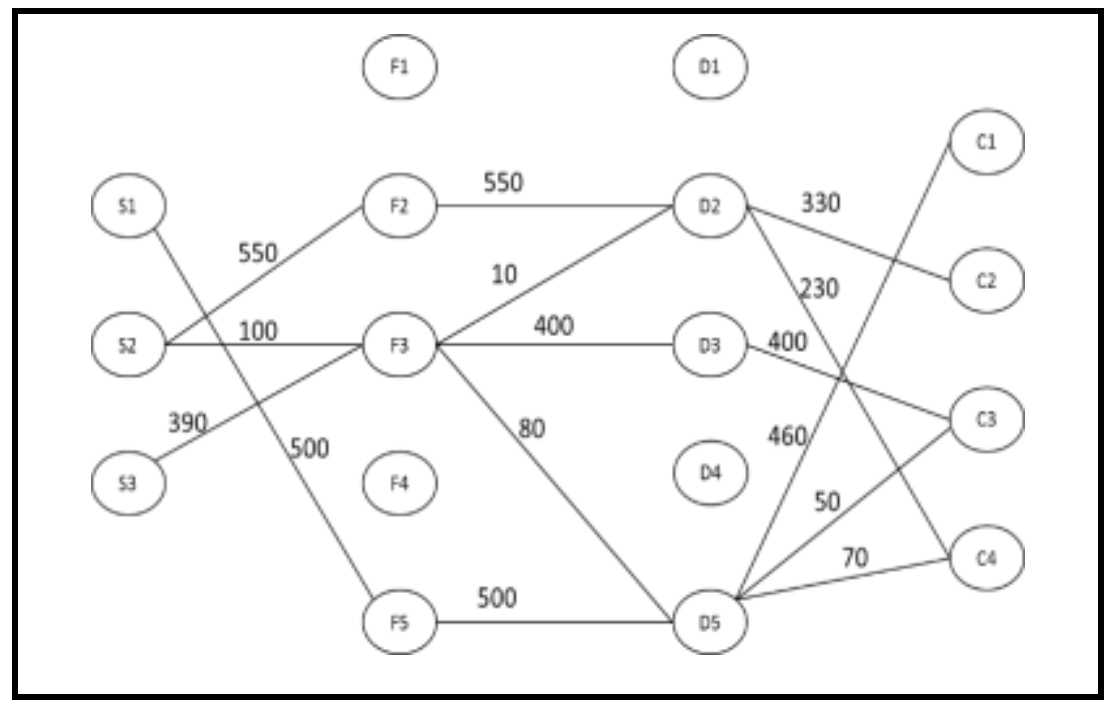

Figure 3. The Results of Transshipment Problem

According to the results of the models, 2nd, 3rd and 5th facilities and 2nd, 3rd and 5th DCs must be established.

In the solution performed with Hannan approach, $\lambda=0.03$ and the values of deviation variables were found to be $d_{1}^{-}=0.65, d_{1}^{+}=0, d_{2}^{-}=0.33, d_{2}^{+}=0, d_{3}^{-}=0$ and $d_{3}^{+}=0.97$ and in the solution performed with Chen approach, it was found to be $\lambda=0.03$ ve $\lambda^{\prime}=0.97$.

The cost of 3 facilities planned to be established.

$$
\begin{aligned}
& \text { Cost }_{p}=1800 w_{1}+900 w_{2}+2100 w_{3}+1100 w_{4}+900 w_{5} \\
& \text { Cost }_{p}=1800 \times 0+900 \times 1+2100 \times 1+1100 \times 0+900 \times 1 \\
& \text { Cost }_{p}=3900
\end{aligned}
$$

The cost of 3 DC suggested to be established

$$
\begin{aligned}
& \text { Cost }_{D C}=1000 z_{1}+900 z_{2}+1600 z_{3}+1500 z_{4}+1400 z_{5} \\
& \text { Cost }_{D C}=1000 \times 0+900 \times 1+1600 \times 1+1500 \times 0+1400 \times 1 \\
& \text { Cost }_{D C}=3900
\end{aligned}
$$

Transportation cost of the recommended model

$$
\begin{aligned}
\operatorname{Cost}_{\text {ship }}= & 5 x_{15}+5 x_{22}+6 x_{23}+3 x_{33}+7 y_{22}+7 y_{32}+4 y_{33}+ \\
& 4 y_{35}+3 y_{55}+4 z_{22}+7 z_{24}+3 z_{33}+4 z_{51}+5 z_{53}+7 z_{54} \\
\text { Cost }_{\text {ship }}= & 5 \times 500+5 \times 550+6 \times 100+3 \times 390+7 \times 550+7 \times 10+4 \times 400+ \\
& 4 \times 80+3 \times 500+4 \times 330+7 \times 230+3 \times 400+4 \times 460+5 \times 50+7 \times 70 \\
\text { Cost }_{\text {ship }}= & 20820
\end{aligned}
$$




\section{Conclusions and Recommendations}

In today's rivalry environment, the administrators face with high cost in intrabusiness transportation problem. In this case, business administrators apply to quantitative analysis techniques to reduce the expenses. In the study, FGP that is one of the quantitative methods was used solution techniques of transshipment problem. In the application, 3-stage transshipment problem including 3 suppliers, 5 facilities, 5 Distributing Centers and 4 customers was modeled as FGP in the study. The transshipment problem formed was modeled in accordance with FGP approach of Hannan and Chen and solved WinQSB application program.

The same results were obtained with both approaches. In accordance with the targets identified by the decision makers, it was determined to set up 2nd, 3rd and 5th facilities and ve 2nd, 3rd and 5th DCs. The transportation amounts from the suppliers to the facilities, the transportation amounts from the facilities and DCs and the transportation amounts from DCs to the customers are given in Table 4. The total cost was found to be 28620 unit that is the total of 3 facilities required to be established (set up cost 3900), 3 DC costs (set up cost 3900) and the transportation costs between each unit and (set up amounts 20820).

While constraints are being formed in the models, it was made use capacities of the sources, the facilities and distributing centers. In the models suggested, absolute constraints were used. With the solution of the models, the transportation amounts between the units and the results of which facilities and distributing centers must be opened were found successfully. With this study, it has been indicated that transshipment problems can be modelling of with FGP model and solved efficiently in accordance with the targets identified by the decision makers.

\section{Acknowledgments}

This paper is a revised and expanded version of a paper entitled [Modelling of Transshipment Problem with Fuzzy Goal Programming] presented at [5th World Conference on Business, Economics and Management, Kemer - TURKEY and 12 - 14 May 2016].

\section{References}

[1] P. Güçlü and A. Özdemir, "Bulanık hedef programlama ile tedarik zinciri optimizasyonu: tekstil sektöründe bir uygulama”, Hacettepe Üniversitesi İktisadi ve İdari Bilimler Fakültesi Dergisi, vol. 33, no. 1, (2015), pp.79-100.

[2] S. Alp, "Doğrusal hedef programlama yönteminin otobüsle kent içi toplu taşıma sisteminde kullanılması", İstanbul Ticaret Üniversitesi Fen Bilimleri Dergisi, vol. 7, no. 13, (2008), pp. 73-91.

[3] J. M. Martel and A. Belaid, "Diverse imprecise goal programming model formulations", Journal of Global Optimization, vol. 12, no. 2, (1998), pp. 127-138.

[4] E. L. Hannan, "On Fuzzy Goal Programming”, Decision Sciences, vol. 12, no. 3, (1981), pp. 523-531.

[5] R. N. Tiwari, S. Dhamar and J. R. Rao, "Fuzzy goal programming: an additive model", Fuzzy sets and systems, vol. 24, no. 1, (1987), pp. 27-34.

[6] T. Yang, J. Ignizio and H. J. Kim, "Fuzzy programming with nonlinear membership function: piecewise linear approximation", Fuzzy sets and systems, vol. 41, no. 1, (1991), pp. 39-53.

[7] Y. W. Chen and M. Larbani, "Two-Person Zero-Sum game approach for fuzzy multiple decision making problems", Fuzzy sets and systems, vol. 157, no. 1, (2006), pp. 34-51.

[8] S. Erpolat, "Üretim planlamasinda hedef programlama ve bulanik hedef programlama yöntemlerinin karşilaştirilmasi”, Öneri Dergisi, vol. 9, no. 34, (2010), pp. 233-246.

[9] P. A. Rubin and R. Narasimhan, "Fuzzy goal programming with nested priorities", Fuzzy Sets and Systems, vol. 14, no. 2, (1984), pp. 115-129.

[10] R. Bellman and L. Zadeh, "Decision making in a fuzzy environment", Management Science, vol. 17, no. 4, (1970), pp. 141-164.

[11] A. Syarif, Y. Yun and M. Gen, "Study on multi-stage logistic chain network; a spanning tree-based genetic algorithm approach", Computers and Industrial Engineering, vol. 43 no. 1-2, (2002), pp. 299-314.

[12] H. K. Chen, "A Note on a fuzzy goal programming algorithm by Tiwari, Dhamar, and Rao", Fuzzy Sets and Systems, vol. 62, no. 3, (1994), pp. 287-290. 
[13] M. Kumar, V. Prem and R. Shankar, "A fuzzy goal programming approach for vendor selection problem in a supply chain", Computers and Industrial Engineering, vol. 46, no. 1, (2004), pp. 299-31.

[14] H. Selim, C. Araz and I. Ozkarahan, "Collaborative production-distribution planning in supply chain: A fuzzy goal programming approach", Transportation Research Part E, vol. 44, no. 1, (2008), pp. 396-419.

[15] M. A. Parra, A. B. Terol and M. V. R. Uria, "A Fuzzy Goal Programming Approach to Portfolio Selection", European Journal of Operational Research, vol. 133, no. 1, (2001), pp. 287-297.

[16] H. P. Sharma, D. K. Sharma and R. K. Jana, "Credit Union Portfolio Management - An Additive Fuzzy Goal Programming Approach”, International Research Journal of Finance and Economics, vol. 30, no. 1, (2009), pp. 18-29.

[17] S. P. Rout, "Traffic Management and QOE in MPLS Network based on Fuzzy Goal Programming", International Journal of Innovative Research in Science, Engineering and Technology, vol. 5, no. 5, (2016), pp. 8053-8058.

[18] A. Biswas and A. K. A. De, "Fuzzy Goal Programming Approach for Solid Waste Management under Multiple Uncertainties”, Procedia Environmental Sciences, vol. 35, no.1, (2016), pp. 245-256.

[19] Y. Kinoshita, T. Yamada, S. M. Gupta, A. İshigaki and M. Inoue, "Disassembly parts selection and analysis for recycling rate and cost by goal programming", Journal of Advanced Mechanical Design, System and Manufacturing, vol. 10, no. 3, (2016), pp. 1-15.

[20] M. H. Mehrolhassani and V. K. Jahromi, "Application of goal programming to improve human resource allocation for urban family physician plan in Iran”, Journal of Health Management \& Informatics, vol. 3, no. 3, (2016), pp. 94-99.

[21] A. L. D. Augustynczik, J. E. Arce and A. C. L. Silva, "Aggregating forest harvesting activities in forest plantations through Integer Linear Programming and Goal Programming", Journal of Forest Economics, vol. 24 , no. 1, (2016), pp. 72-81.

[22] B. Mishra and S. R. Singh, "Optimal Land Allocation in Agricultural Production Planning Using Fuzzy Goal Programming”, Advances in Intelligent System and Computing, vol. 436, no. 1, (2016), pp. 287-298. 